\title{
A SURVEY ON OPPORTUNITY, SCOPE AND POSSIBILITIES OF YOGA INTERVENTION IN MODERN CHINA
}

\author{
Amit Chandra Deshmukh ${ }^{1}$, \\ Avinash Mishra², \\ Li Youqiang ${ }^{3 i}$ \\ ${ }^{1}$ Doctoral Student, \\ Shanghai University of Sport, \\ Department of Physical Education, \\ Sports Coaching \& Training, \\ Shanghai, China \\ ${ }^{2}$ Doctorate, \\ Director Vivekananda Cultural Communication Co. Ltd., \\ Shanghai, China \\ ${ }^{3}$ Professor, Shanghai University of Sport, \\ Department of Physical Education, \\ Sports Coaching \& Training, \\ Shanghai, China
}

\begin{abstract}
:
The purpose of this study was to find out the scope, facilities and possibilities of Yoga intervention in China. For the purpose of this study, 201 samples i.e. yoga instructors (22); yoga studio owners (7); yoga instructors plus yoga studio owners (8) yoga practitioners (113) yoga lovers (50) and others (1) from various provinces and cities from China were randomly selected. The subjects' age ranged between $60^{+}$to $90^{+}$years. To find out the scope, facilities and possibilities of Yoga intervention in China, a questionnaire made by "Vivekananda Cultural Communication (Shanghai) Co. Ltd." based on "Daily Yoga Courses and Training Content in China" were introduced. For statistical analysis and interpretation of data, descriptive statistics of selected variables and descriptive statement analysis method were conducted. Interestingly this study found a very high level of scope, facilities and realistic possibilities of Yoga intervention in China which directly or indirectly might be help to develop yoga industries in China and also can better understand the need and interest of yoga for health and wellbeing among Chines population in new era.
\end{abstract}

Keywords: Yoga, China, scope, facilities, possibilities

\footnotetext{
i Correspondence: email deshmukh.chandra@gmail.com, avinash mishra3@hotmail.com, youmecity@163.com
} 


\section{Introduction}

The Sanskrit root "Yuj" means to "Yoke," "Bind," or "Join Together." It also indicates "Union" or "Oneness." In a deeper spiritual level, yoga allows us to reveal the inner Self, the True Essence of our Being. Actually, it is the means by which we realize that there is no separation between anyone and anything. Everything is "One". According to the Yoga Shikha Upanishad: "Verily, there is no virtue greater than Yoga, no good greater than Yoga, and no subtlety greater than Yoga". Yoga is an empirical science and philosophy aimed at understanding life's most important questions. Yoga was first popularized in China through the television programmers of Wai Lana (Zhang Huilan) in the 1980s on China Central Television (CCTV). It took hold in Hong Kong in these early years, but in recent decades, and especially in the past five years, yoga has rapidly grown in popularity, especially among China's emerging middle class. Nearly two thousand years ago with Buddhism, yoga entered into a cultural world that already has its own counterparts to compete against popularity. In China, several physical and mental disciplines already exist that may seem to overlap with yoga, including various martial arts and, most notably, qigong and tai chi. Yoga and tai chi have both come to represent important aspects of Indian and Chinese culture, respectively. As cultural icons representing the embodiment of ancient virtues, the two disciplines have been used in everything from Olympic ceremonies to international commemorations or credit card advertisements.

This dramatic turn from cultural scapegoat to national hero coincides with an increasing mood of cultural and nationalist confidence in China, particularly since the ascent of Party General Secretary and President Xi Jinping in 2012. An increase in cultural confidence is also apparent in India, although in a different way. With the election of Narendra Modi as Prime Minister, Hindu nationalism seems to be on the rise in India. In the view of some critics, Modi came to power in 2014 under a cloud of concern about whether he would offer equal treatment to Hindus, Muslims and Sikhs. Less than a year into his first term in office Modi make the United Nations officially recognize June 21 as the International Day of Yoga. As Modi has noted, state support of yoga has served to expand its influence and preserve the tradition. This symbiotic relationship between yoga and the state also sees yoga being used by Modi and the Indian state as an olive branch and gesture of cultural goodwill in ceremonies that celebrate Sino-Indian cooperation. Irrespective of state relations, yoga still belongs to the people. Susan (Sixue) Jia has written about the various motivations for yoga practitioners in China in recent years in her study of the subject. She finds that they seek a number of outcomes from yoga, including physical and psychological health, beauty, and social connections. While these are all valid benefits to be obtained from yoga practice, Jia refers to yoga practitioners as 'yoga consumers'. Yoga in China seems to have acquired some of the global cachet that makes it an expensive activity around the world. In the cultures of consumption that exist in both the US and China, the daily or monthly fees, along with the designer clothing, bags and water bottles, are all part of the yoga experience as it has been redefined. Many observers have long been concerned about the commercialization of yoga around the 
world, and China is no exception. With the focus on the more physical aspects of yoga, it is possible that the practice is thus kept safe from government attention. The spiritual element of yoga could potentially raise eyebrows in Beijing. Yoga in China seems to be safe in the realm of relieving stress, cultivating beauty, fitness, and building community. Cultural exchanges between India and China along with what we now call the Silk Roads (so named by a nineteenth-century German geographer) go back many centuries, and they have seen periods of blossoming, neglect and hostility. Today, Beijing aims to establish a 'New Silk Road', a massive infrastructure development initiative which is also referred to as the Belt and Road Initiative (BRI) or the One Belt One Road (OBOR, Yi dai yi lu, 一带一路). As with Sino-Indian relations in previous eras, this one is fraught with tensions, but also great potential. Yoga is one avenue that has been used by both New Delhi and Beijing to represent symbolic cooperation and even harmony between the two states and their respective cultures. In comparison with Buddhism, yoga is still a relatively recent import into China, but it seems one that is likely to make significant inroads. Yoga appeals specifically to practitioners seeking relief from their stressful work environment, and it has taken root in the booming economy of China.

\section{Methods}

For the purpose of this study, 201 samples i.e. yoga instructors (22); yoga studio owners (7); Yoga instructors plus yoga studio owners (8); Yoga practitioners (113); Yoga lovers (50) and others (1) from various provinces like, Shanghai Province, Zhejiang Province, Guangdong Province, Hubei Province, Henan Province, Gansu province, Shaanxi Province, Beijing Province, Anhui Province and Chongqing Province and cities like, Shanghai, Hangzhou, Foshan, Jinhua, Guangzhou, Wuhan Zhengzhou, Xianyang, Lishui, Beijing, Bengbu, Changsha, Xingtai, Jinhua, Huizhou, Chongqing, Zhoukou, Wenzhou, Nanjing, Lishui, Weihai, Tangshan, Qingdao, Xiamen, Tangshan and Langfang etc. from China were randomly selected. The participant of this survey were professionally associated with some professions like, Full-time worker (137); Part-time job holder (7); Freelancer (40) Students (11) and others (6). The subjects' age ranged between $60^{+}$to $90^{+}$years. To find out the scope, facilities and possibilities of Yoga intervention in China, a questionnaire made by "Vivekananda Cultural Communication (Shanghai) Co. Ltd." based on "Daily Yoga Courses and Training Content in China" were introduced in the study. For statistical analysis and interpretation of data, descriptive statistics of selected socio-psychological variables and descriptive statement analysis method were conducted respectively. 


\section{Results}

Table 1: Descriptive Statistics and graphs of Identity, Gender and Age

\begin{tabular}{|c|c|c|}
\hline \multicolumn{3}{|c|}{ Participants' Identity } \\
\hline Options & Statistics & \multirow{8}{*}{ Yoga lovers $25 \%$} \\
\hline Yoga instructor & 22 & \\
\hline Yoga studio owner & 07 & \\
\hline Both of the above & 08 & \\
\hline Yoga practitioner & 113 & \\
\hline Yoga lovers & 50 & \\
\hline Others & 01 & \\
\hline Total & 201 & \\
\hline \multicolumn{2}{|l|}{ Participants' Gender } & \multirow{5}{*}{ omen $97 \%$} \\
\hline Men & 6 & \\
\hline women & 195 & \\
\hline Total & 201 & \\
\hline & & \\
\hline \multicolumn{3}{|l|}{ Participants' Age } \\
\hline & & \multirow{7}{*}{60 to 70 years $10 \%$} \\
\hline 90 years and above & 50 & \\
\hline 80 to 90 years & 84 & \\
\hline 70 to 80 years & 46 & \\
\hline 60 to 70 years & 21 & \\
\hline \multirow[t]{2}{*}{ Total } & 201 & \\
\hline & & \\
\hline
\end{tabular}

Table 1 shows participants' identity: as 11\% yoga instructor; $3 \%$ yoga studio owner, $4 \%$ both of the above; $56 \%$ Yoga practitioner; $25 \%$ yoga lovers and others $0 \%$. In participants' gender: $3 \%$ men and 97\% women and in participants' age: $25 \%$ participants were 90 years and above; $42 \%$ participants were in between 80 to 90 years; $23 \%$ participants were in between 70 to 80 years; and 10\% participants were in between 60 to 70 years. 
Table 2: Basic Descriptive Statistics and graph of duration of yoga practice/year/week/day

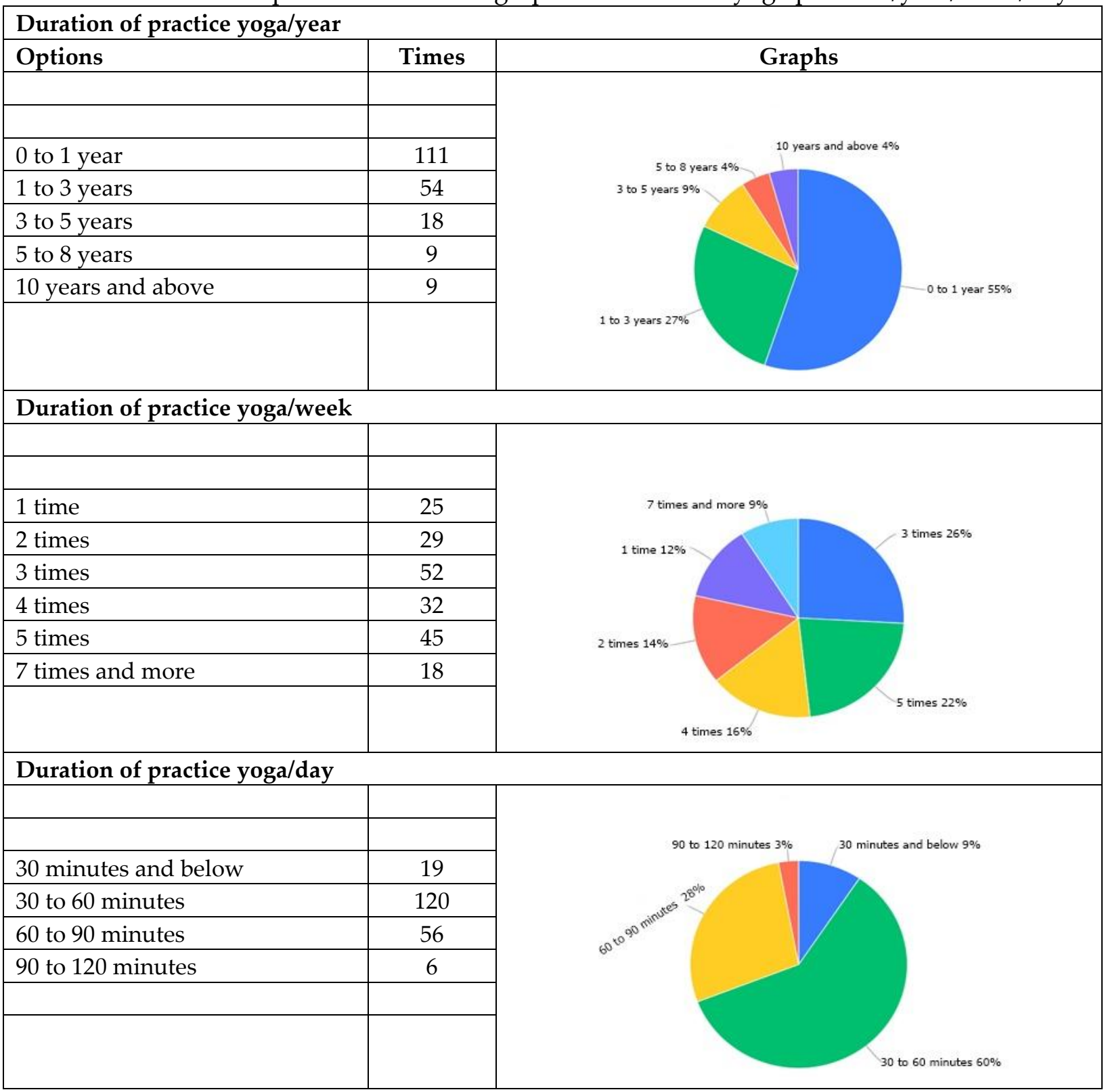

Table 2 shows participants' duration of yoga practice/year: 55\% participants were practicing yoga for 0 to 1 year; $27 \%$ participants were practicing yoga for 1 to 3 years; $9 \%$ participants were practicing yoga for 3 to 5 years; $4 \%$ participants were practicing yoga for 5 to 8 years and $4 \%$ participants were practicing yoga for 10 years and above. In the section of participants' duration of yoga practice/week: $12 \%$ participants were practicing yoga 1 time/week; $14 \%$ participants were practicing yoga 2 times/week; $26 \%$ participants were practicing yoga 3 times/week; 16\% participants were practicing yoga 4 times/week; $22 \%$ participants were practicing yoga 5 times/week; and $9 \%$ participants were practicing yoga 7 times and more/week. The participants' duration of yoga practice/day: 9\% participants were practicing yoga for 30 minutes and below/day; 60\% participants were 
practicing yoga 30 to 60 minutes/day; $28 \%$ participants were practicing yoga 60 to 90 minutes/day; $3 \%$ participants were practicing yoga 90 to 120 minutes/day.

Table 3: The statistics and graph of interest of Chinese People

to participate in various Courses and Workshops in Yoga

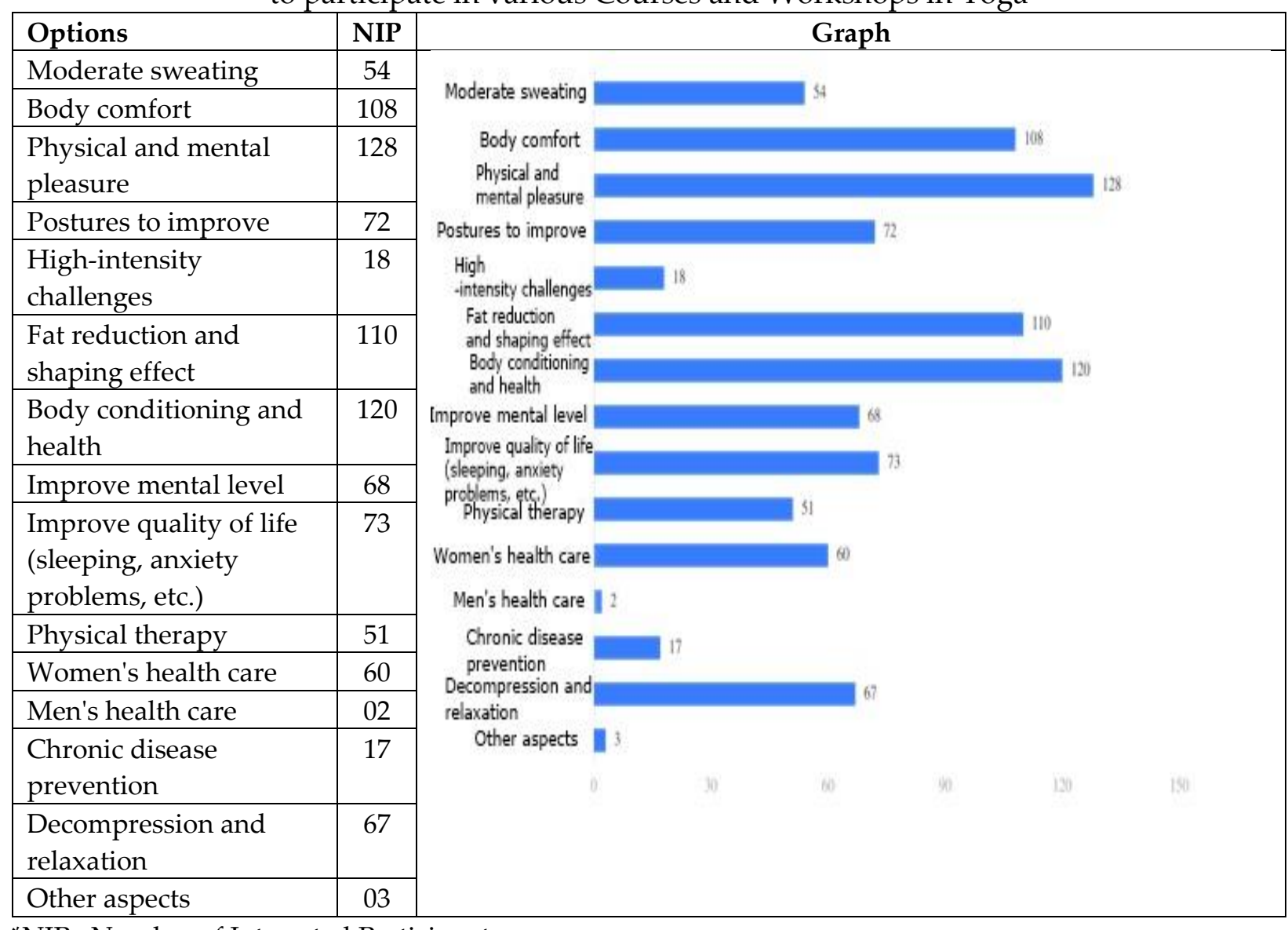

${ }^{*} \mathrm{NIP}=$ Number of Interested Participants

Table 3 shows the interest of NIP to participate in various courses and workshops in Yoga i.e. Moderate sweating (54); Body comfort (108); Physical and mental pleasure (128); Postures to improve (72); High-intensity challenges (18); Fat reduction and shaping effect (110); Body conditioning and health (120); Improve mental level (68); Improve quality of life (sleeping, anxiety problems, etc.) (73); Physical therapy (51); Women's health care (60); Men's health care (02); Chronic disease prevention (17); Decompression and relaxation (67); and Other aspects (03). 
Table 4: The statistics and graph of interest of Chinese people to participate training program of Yogic Physiotherapy

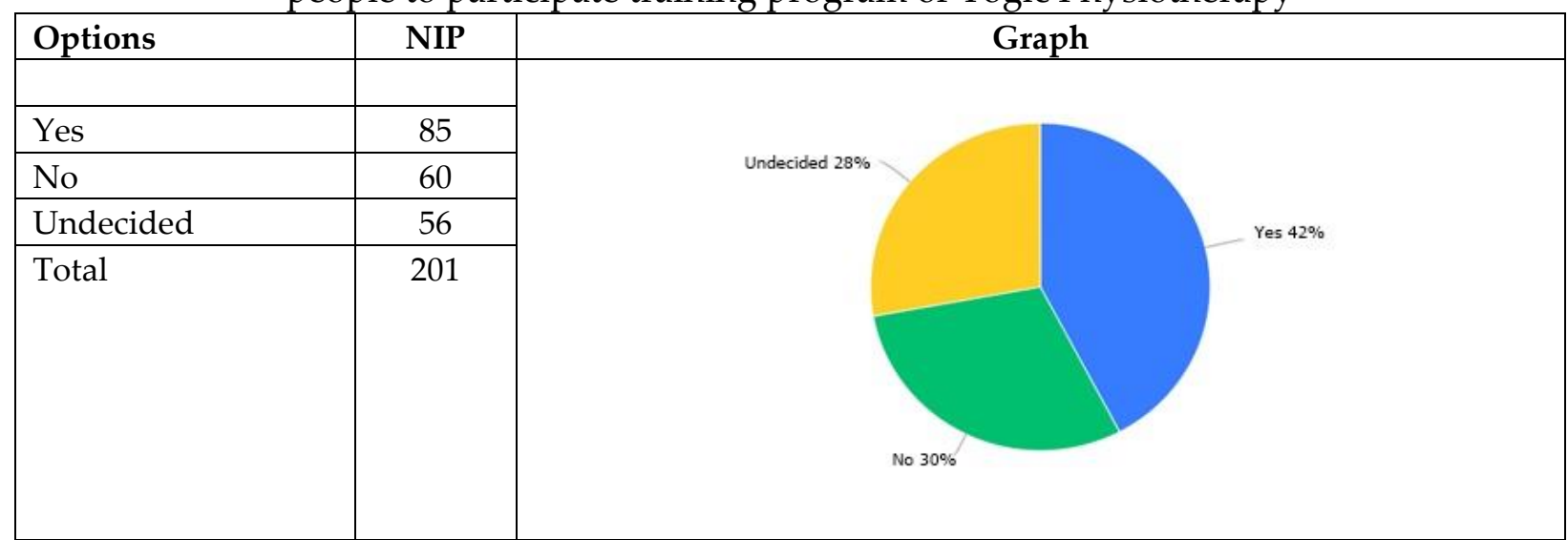

${ }^{*} \mathrm{NIP}=$ Number of Interested Participants

Table 4 shows $42 \%$ NIP were interested to take part in yogic physiotherapy; $30 \%$ NIP were not interested to take part in yogic physiotherapy, while $28 \%$ NIP were still undecided.

Table 5: The statistics and graph of possibility of Chinese people to go other provinces or cities to participate in training or workshops in Yoga

\begin{tabular}{|c|c|c|c|}
\hline Critical (0-6) & Passive (7-8) & Recommended (9-10) & Net recommendation score \\
\hline $87.06 \%$ & $3.48 \%$ & $9.45 \%$ & $-77.61 \%$ \\
$175 \mathrm{NIP}$ & $7 \mathrm{NIP}$ & $19 \mathrm{NIP}$ & \\
\hline
\end{tabular}

${ }^{*} \mathrm{NIP}=$ Number of Interested Participants

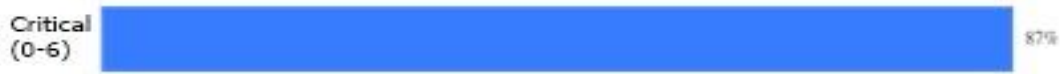

Table 5 shows the possibility of NIP to go other provinces or cities to participate in training or workshops in Yoga. $87.06 \%$ or 175 NIP felt critical to visit other provinces or cities to participate in training or workshops in Yoga; 3.48\% 7 NIP felt passive to visit 
other provinces or cities; and 9.45\% 19 NIP felt no problem to visit other provinces or cities to participate in training or workshops in Yoga.

Table 6: The statistics and graph of Physical and mental status of Chinese people

\begin{tabular}{|l|c|c|c|c|}
\hline & $\begin{array}{c}\text { Absolutely } \\
\text { not }\end{array}$ & $\begin{array}{c}\text { As } \\
\text { usual }\end{array}$ & $\begin{array}{c}\text { More } \\
\text { than usual }\end{array}$ & $\begin{array}{c}\text { Much more } \\
\text { than usual }\end{array}$ \\
\hline Feel the need to nourish & 25 & 88 & 36 & 3 \\
\hline Feeling weak & 41 & 76 & 30 & 5 \\
\hline Feeling sick & 73 & 57 & 20 & 2 \\
\hline Feeling headaches & 68 & 57 & 26 & 1 \\
\hline Feel tightness or pressure on their head & 65 & 55 & 29 & 3 \\
\hline Feeling cold or hot & 90 & 49 & 10 & 3 \\
\hline
\end{tabular}

*The answers of NIP 152/201

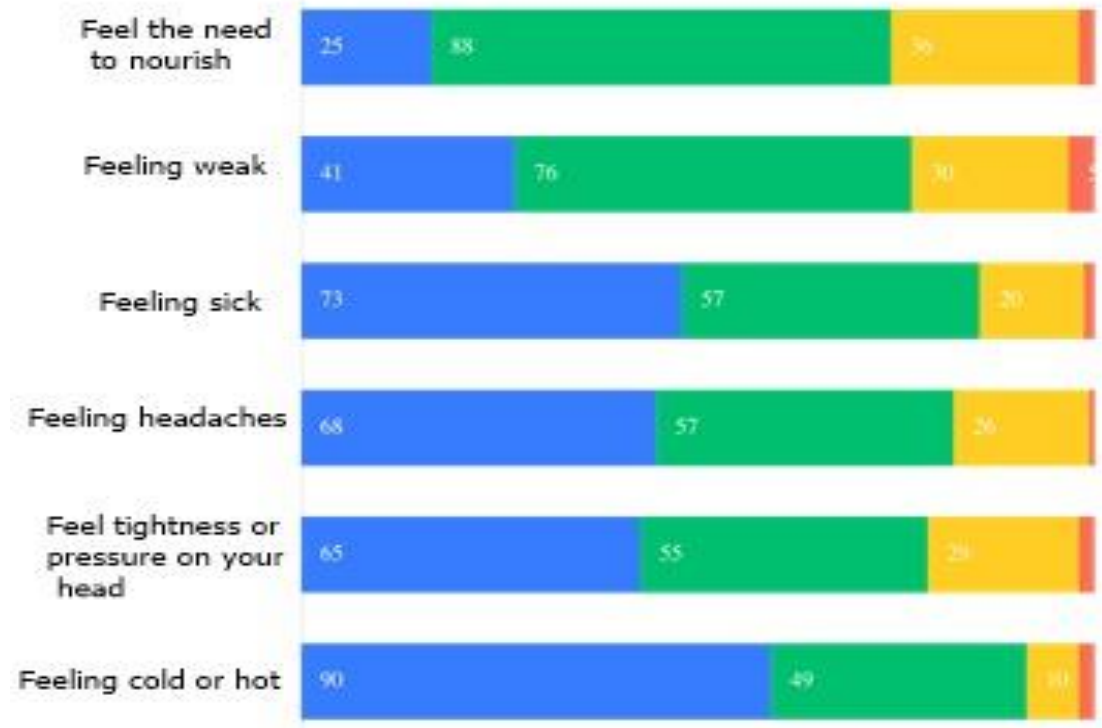

Absolutely not As usual More than usual Much more than usual

Table 6 shows the Physical and mental status NIP in their day to day life i.e. majority of NIP feel as usual the need to nourish their health; majority of NIP feel as usual in feeling weakness; majority of NIP did not feel sick at all; majority of NIP did not feel headaches in daily life; majority of NIP also did not feel tightness or pressure on their head; majority of NIP also did not feel cold or hot in their day to day life. 
Table 7: The statistics and graph of busyness of Chinese people in their daily life

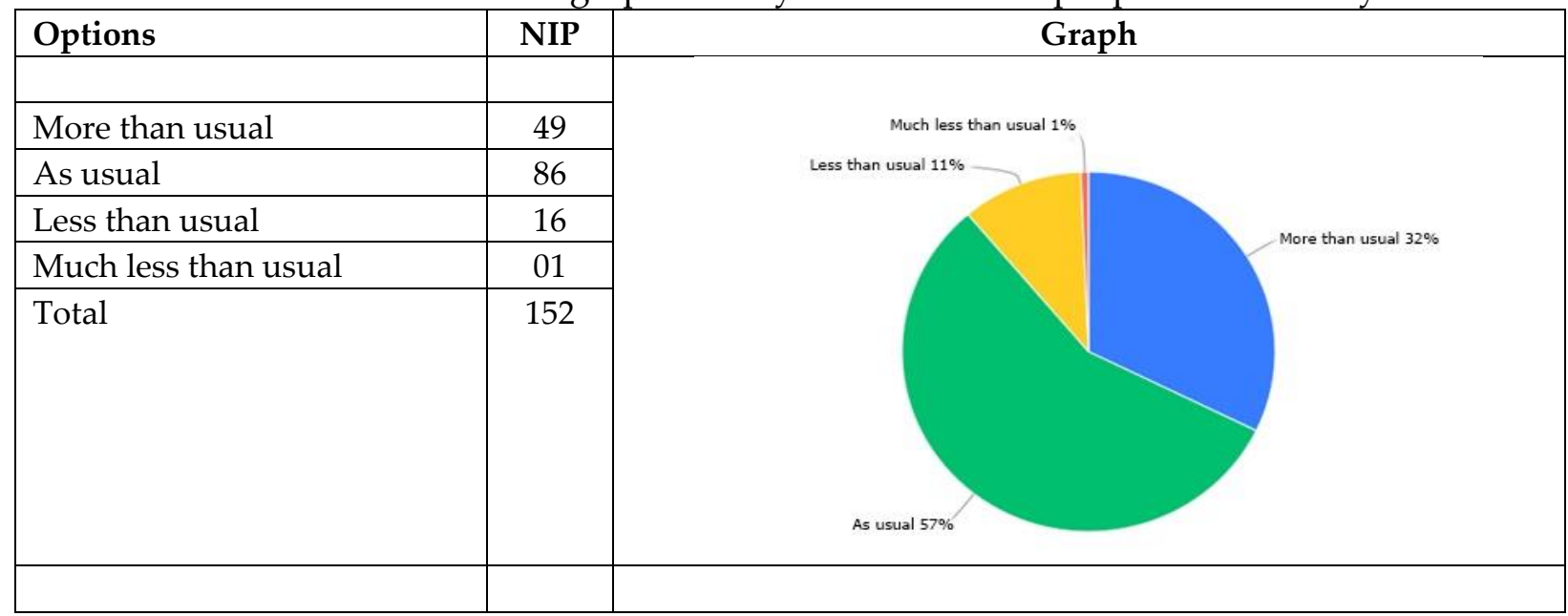

${ }^{*} \mathrm{NIP}=$ Number of Interested Participants

Table 7 shows busyness of NIP in their daily life i.e. 32\% NIP felt busy more then as usual; $57 \%$ NIP fell busy as usual; 11\% NIP felt busy less than usual; and 1\% NIP felt busy much less than usual.

Table 8: The statistics and graph of professional wellness of Chinese people

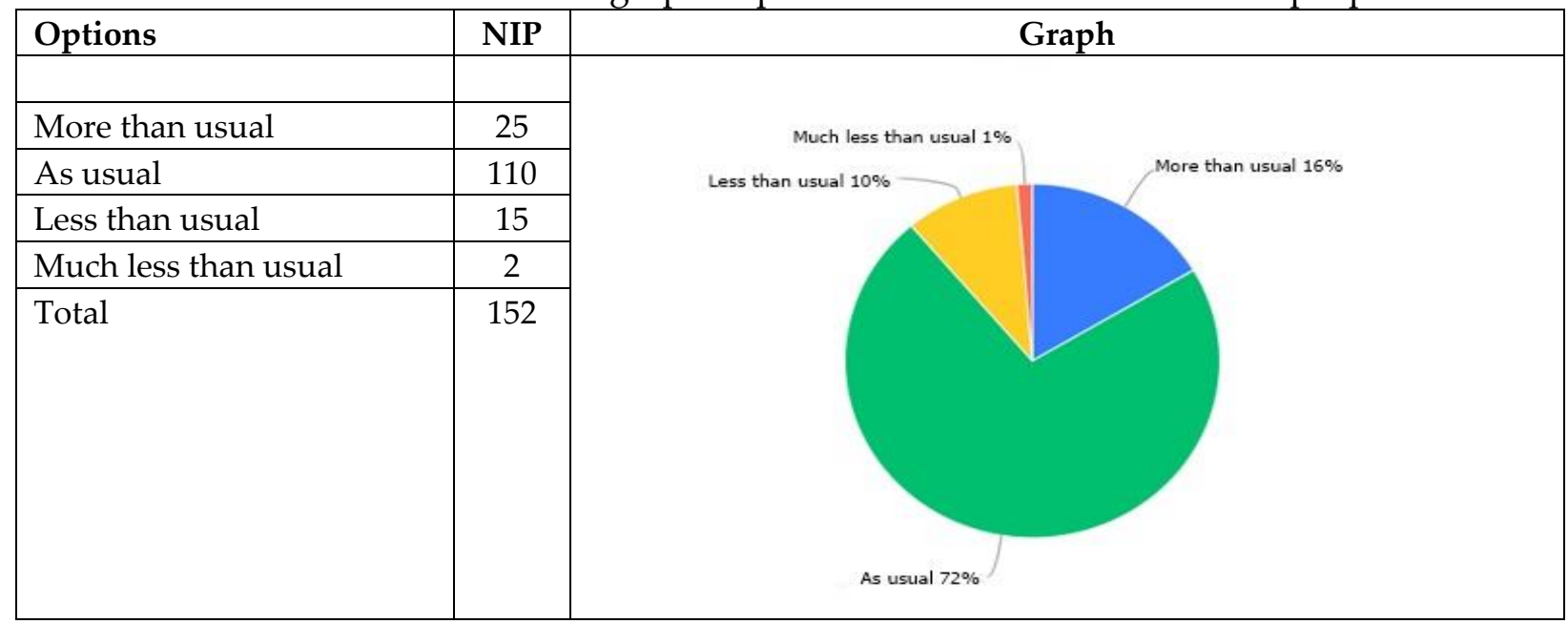

${ }^{*} \mathrm{NIP}=$ Number of Interested Participants

Table 8 shows the professional wellness of NIP i.e. 16\% NIP felt professionally well more then as usual; $72 \%$ NIP fell professionally well as usual; $10 \%$ NIP felt professionally well less than usual; and 1\% NIP felt professionally well much less than usual.

Table 9: The statistics and graph of Job Satisfaction of Chinese people

\begin{tabular}{|l|c|c|}
\hline Options & NIP & \multicolumn{1}{|c|}{ Graph } \\
\hline As usual & & \\
\hline Less than usual & 100 & \\
Much less than usual & 25 & \\
\hline Very satisfied & 7 & \\
\hline
\end{tabular}




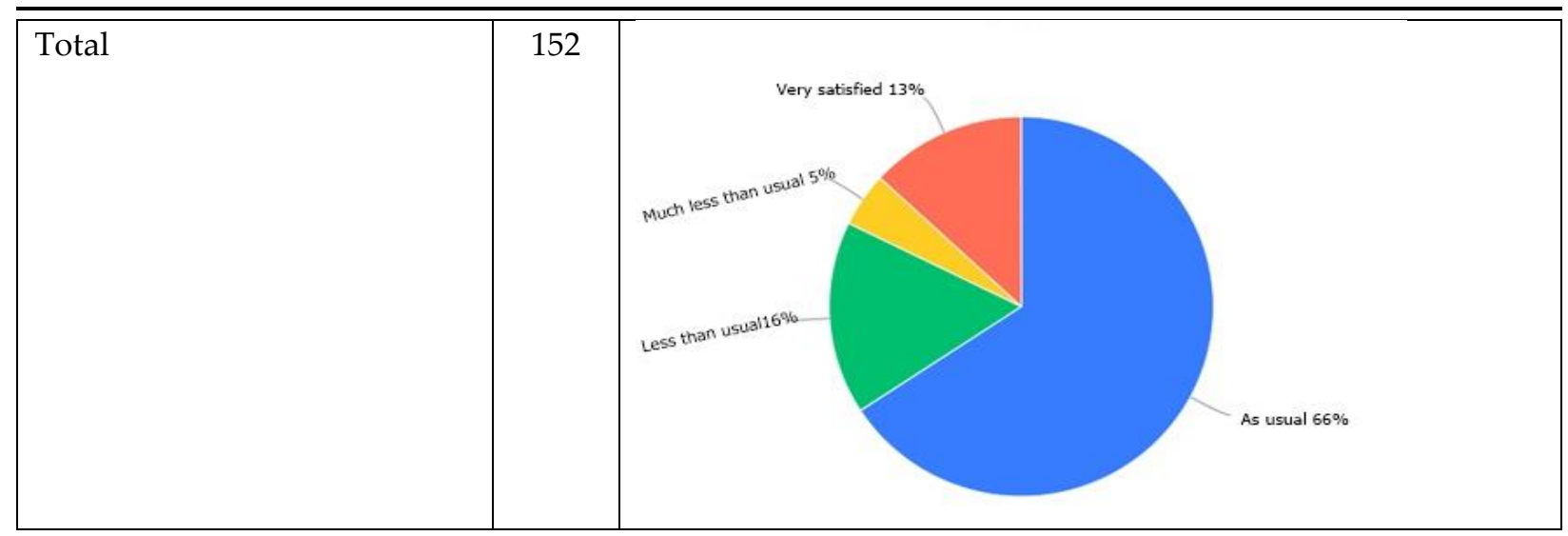

*NIP= Number of Interested Participants

Table 9 shows the Job Satisfaction of NIP i.e. $66 \%$ NIP felt as usual in Job Satisfaction; $16 \%$ NIP felt less than usual in Job Satisfaction; 5\% NIP felt much less than usual in Job Satisfaction and 13\% NIP fell very satisfied in their job.

Table 10: The statistics and graph of decisions making capacity of Chinese people

\begin{tabular}{|l|c|c|}
\hline Options & NIP & \multicolumn{1}{|c|}{ Graph } \\
\hline More than usual & & \\
\hline As usual & 29 & \\
\hline Less than usual & 109 & \\
\hline Much less than usual & 13 & \\
\hline Total & 152 & \\
& & \\
& & Less than usual 9\% less than usual 1\% \\
& & \\
\hline
\end{tabular}

*NIP= Number of Interested Participants

Table 10 shows the decisions making capacity of NIP i.e. 19\% NIP felt more then as usual in decisions making capacity; 72\% NIP fell as usual in decisions making capacity; 9\% NIP felt less than usual in decisions making capacity; and 1\% NIP felt much less than usual in decisions making capacity.

Table 11: The statistics and graph of fun of daily activity of Chines people

\begin{tabular}{|l|c|c|}
\hline Options & NIP & \multicolumn{1}{|c|}{ Graph } \\
\hline & & \\
\hline More than usual & 35 & \\
\hline As usual & 85 & \\
\hline Less than usual & 27 & \\
\hline Much less than usual & 5 & \\
\hline
\end{tabular}




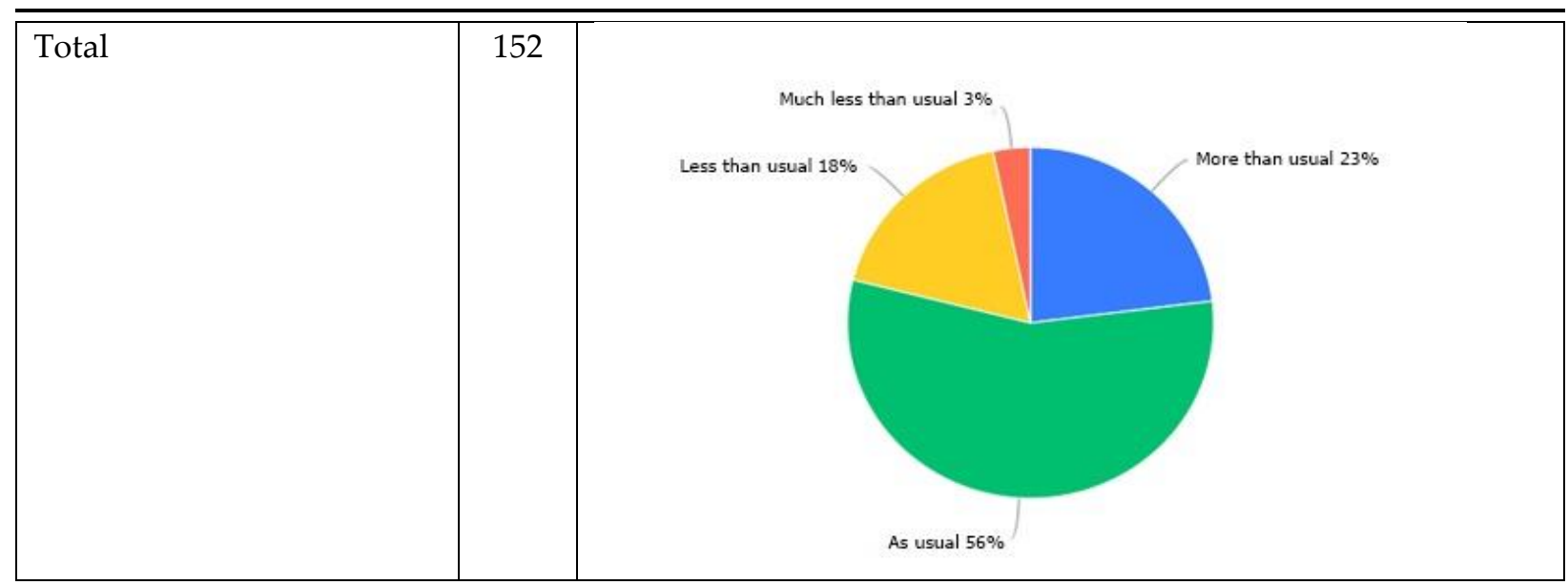

${ }^{*} \mathrm{NIP}=$ Number of Interested Participants

Table 11 shows the fun of daily activity of NIP i.e. $25 \%$ NIP felt more then as usual in fun of daily activity; $56 \%$ NIP fell as usual in fun of daily activity; $18 \%$ NIP felt less than usual in fun of daily activity; and 3\% NIP felt much less than usual in fun of daily activity.

Table 12: The statistics and graph of not worth living in life of Chinese people

\begin{tabular}{|l|c|c|}
\hline Options & NIP & \\
\hline & & \\
\hline Absolutely not & 103 & Graph \\
\hline As usual & 39 & \\
\hline More than usual & 8 & \\
\hline Much less than usual & 2 & As usual 26\% \\
\hline Total & 152 & \\
& & \\
\end{tabular}

${ }^{*} \mathrm{NIP}=$ Number of Interested Participants

Table 12 shows not worth living in life of NIP i.e. $68 \%$ NIP felt absolutely not in not worth living in life; $26 \%$ NIP fell as usual in not worth living in life; $5 \%$ NIP felt More than usual in not worth living in life; and 1\% NIP felt much less than usual in not worth living in life.

Table 13: The statistics and graph of nervousness of Chines people

\begin{tabular}{|l|c|c|}
\hline Options & NIP & \multicolumn{1}{|c|}{ Graph } \\
\hline & & \\
\cline { 1 - 2 } Absolutely not & 87 & \\
As usual & 49 & \\
\cline { 1 - 2 } More than usual & 13 & \\
\cline { 1 - 1 } Much less than usual & 3 & \\
\hline
\end{tabular}




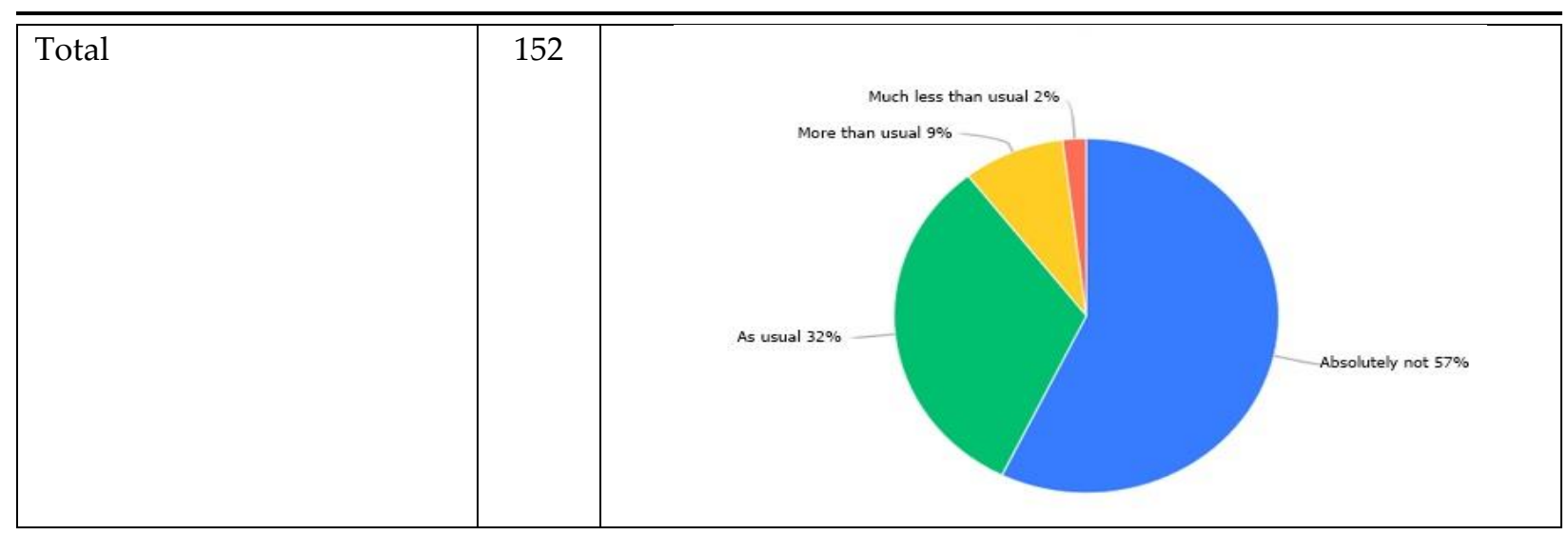

*NIP= Number of Interested Participants

Table 13 shows nervousness of NIP i.e. 57\% NIP felt absolutely not in nervousness in life; $32 \%$ NIP fell as usual in nervousness in life; 9\% NIP felt More than usual in nervousness in life; and $2 \%$ NIP felt much less than usual in nervousness in life.

Table 14: The statistics and graph of thought of committing suicide of Chines people

\begin{tabular}{|c|c|c|}
\hline Options & NIP & Graph \\
\hline Certainly not & 130 & Sure th \\
\hline I do not think so & 14 & Sometimes have such thoughts $4 \%$ \\
\hline Sometimes have such thoughts & 6 & I do not think so 9\% \\
\hline Sure there is & 2 & \\
\hline Total & 152 & \\
\hline
\end{tabular}

${ }^{*} \mathrm{NIP}=$ Number of Interested Participants

Table 14 shows the thought of committing suicide of NIP i.e. 86\% NIP Certainly did not think of committing suicide; $9 \%$ did not think so in life; $4 \%$ NIP Sometimes have the thought of committing suicide in life; and $2 \%$ NIP really felt to commit suicide.

\section{Conclusions}

Based on the result of this study, it can be concluded that Yoga is getting very popular in China and attended primarily by most of the women. Entry-level classes focus on the physical aspects of Yoga asana, although there is also a growing interest in yoga as a physiotherapy in China. The Chinese people interest to take part in various workshop in yoga are also very high. With the growing popularity of Yoga in China, there is a growing interest in the business of Yoga. As with more urbanization of modern China the mental status, well-being, job satisfaction, decision making capacity, worth living status and fun 
etc. are gradually deducting. Yoga is the process through which this practical problem in the life of Chinese people could be solved. So the opportunity, scope and future possibility of yogic intervention in China become increased. A number of individuals in China are leaving high-power positions to open Yoga studios. For example, Yogi-Yoga Center is a well-established Yoga studio chain, with 17 Yoga studios in Beijing, and dozens in major cities around China. They have formed a second brand, Blue Lotus Yoga, which is designed to appeal to those who prefer a more simplified form of Yoga with the same well-trained teachers, but at less cost per class. Due to government regulation and a high premium on education in general, Yoga teachers are guaranteed an income and benefits comparable to those of academic school teachers. Like other teachers, Yoga teachers are expected to meet high standards of education and experience. There are as yet no copyright or trademark laws in place for the business of Yoga in China. There are also lots of Yoga organizations that speak for the needs of Yoga teachers and Yoga therapists in China. So, the IAYT popularly known as International Association of Yoga Therapists occupies as a global community and forum for these rapidly expanding fields in China.

\section{Conflict of Interest Statement}

The authors declare no conflicts of interests.

\section{About the Authors}

Amit Chandra Deshmukh is a Doctoral student in Shanghai University of Sports from the Department of Sports Coaching and Training (2018-2021). His current research interest on rehabilitation therapy for anxiety, depression \& other daily life problems.

Dr. Avinash Mishra is a managing director of Vivekananda Yoga, P. R. of China. His area of research interest is on health benefits of yoga and traditional sports.

Dr. Li Youqiang is a Professor at Shanghai University of Sport at School of Physical Education and Sports Training, P. R. of China. His current research interest is on health promotion.

\section{References}

[1] Thompson WR. Worldwide survey of fitness trends for 2019. ACSM s Health Fit J. 2018; 22(6):10-7.

[2] Li Y, Han J, Liu Y, Miao L, Li X, Wu X. 2018 China fitness trends-an online survey for fitness professionals in China (in Chinese). J Shanghai University Sport.2018; 42(1):41-6.

[3] Li Y, Wang R, Han J, Liu Y, Wang R, Wu X. 2019 China fitness trends - an online survey for fitness professionals in China (in Chinese). J Shanghai University Sport.2019; 43(1):86-92. 
[4] Yoga in China. (2021). Retrieved 21 November 2021, from https://theasiadialogue.com/2019/12/18/yoga-in-china/

[5] Ulrich Timme Kragh (editor), The Foundation for Yoga Practitioners: The Buddhist Yogācārabhūmi Treatise and Its Adaptation in India, East Asia, and Tibet, Volume 1 Harvard University, Department of South Asian studies, 2013, pp. 16, 25.

[6] Stuart Ray Sarbacker, Samādhi: The Numinous and Cessative in Indo-Tibetan Yoga. Suny Press, 2005, pp. 1-2.

[7] Mallinson, James (2013). "The Yogīs' Latest Trick". Journal of the Royal Asiatic Society. Cambridge University Press. 24 (1): 165-180.

[8] McEvilley, Thomas (1981). "An Archaeology of Yoga". Res: Anthropology and Aesthetics.

[9] Richard Gombrich, "Theravada Buddhism: A Social History from Ancient Benares to Modern Colombo." Routledge and Kegan Paul, 1988, p. 44.

[10] Dumoulin, Heinrich; Heisig, James W.; Knitter, Paul F. (2005). Zen Buddhism: a History: India and China. World Wisdom. ISBN 978-0-941532-89-1.

[11] Feuerstein, Georg (2001). The Yoga Tradition: Its History, Literature, Philosophy and Practice. Hohm Press. ISBN 978-1-890772-18-5.

[12] Goldberg, Philip (2010). American Veda. From Emerson and the Beatles to Yoga and Meditation. How Indian Spirituality Changed the West. New York: Harmony Books. ISBN 978-0-385-52134-5. 
Amit Chandra Deshmukh, Avinash Mishra, Li Youqiang

A SURVEY ON OPPORTUNITY, SCOPE AND POSSIBILITIES

OF YOGA INTERVENTION IN MODERN CHINA

Creative Commons licensing terms

Authors will retain the copyright of their published articles agreeing that a Creative Commons Attribution 4.0 International License (CC BY 4.0) terms will be applied to their work. Under the terms of this license, no permission is required from the author(s) or publisher for members of the community to copy, distribute, transmit or adapt the article content, providing a proper, prominent and unambiguous attribution to the authors in a manner that makes clear that the materials are being reused under permission of a Creative Commons License. Views, opinions and conclusions expressed in this research article are views, opinions and conclusions of the author(s). Open Access Publishing Group and European Journal of Physical Education and Sport Science shall not be responsible or answerable for any loss, damage or liability caused in relation to/arising out of conflict of interests, copyright violations and inappropriate or inaccurate use of any kind content related or integrated on the research work. All the published works are meeting the Open Access Publishing requirements and can be freely accessed, shared, modified, distributed and used in educational, commercial and non-commercial purposes under a Creative Commons attribution 4.0 International License (CC BY 4.0). 